\title{
When It's More Difficult, I Just Cram More! An Exploratory Interview Study on Students' Mindsets in Physics
}

\author{
Verena Spatz ${ }^{1 *}$, Laura Goldhorn ${ }^{2}$ \\ ${ }^{1}$ Didaktik der Physik, Fachbereich Physik, Technische Universität Darmstadt, Darmstadt, GERMANY \\ ${ }^{2}$ Institut für Didaktik der Physik, Goethe-Universität Frankfurt am Main, Frankfurt am Main, GERMANY \\ * Corresponding author: verena.spatz@physik.tu-darmstadt.de
}

Received: 22 Jan. 2021 Accepted: 31 Mar. 2021

Citation: Spatz, V., \& Goldhorn, L. (2021). When It's More Difficult, I Just Cram More! An Exploratory Interview Study on Students' Mindsets in Physics. European Journal of Science and Mathematics Education, 9(3), 92-109. https://doi.org/10.30935/scimath/10948

\begin{abstract}
:
In the US, Dweck's research has shown that learners' beliefs about their own capability are crucial for the learning success of children and adolescents. Two ends of this spectrum can be identified: learners who believe that they need an innate talent have a so-called fixed mindset. When difficulties arise, students with a fixed mindset typically do not see any purpose in continuing to try and fail because they believe they lack the necessary talent. On the other hand, learners who believe effort and hard work are key factors to success, have a growth mindset. They typically perceive difficulties as opportunities to improve their skills and therefore, the growth mindset supports learning processes and outcomes. While there are several surveys on this general concept of mindsets, an examination within the context of physics learning has not yet taken place. For this purpose, an exploratory interview study on students' mindsets in physics was conducted in a total sample of $\mathrm{N}=51$ middle school students in Germany and Austria using a standardised interview structure. The interviews were analysed using qualitative content analysis. The results show that the concept of mindsets according to Dweck can be applied to students' beliefs about learning physics, although a majority of $60 \%$ of the students appear to be classified best as a hybrid between the fixed and the growth mindset.

Keywords: growth mindset, fixed mindset, interview study, case study
\end{abstract}

\section{INTRODUCTION}

In his speech at the Rice University in Houston (TX) in 2018, the physics Nobel Prize winner Carl Wieman described expertise in a wide variety of disciplines to be determined by three capabilities: comprehensive factual knowledge, an efficient organizational framework of that knowledge and cognitive abilities to monitor mental processes. Wieman explained that "no one is innately born with these capabilities" but "reaching a high level [...] actually requires many thousands of hours of intense practice." (Rice University, 2018).

In contrast, many physicists seem to be convinced that congenital talent is a predisposition for expertise in their discipline (Leslie et al., 2015). If one takes this view, it seems quite obvious to distinguish those people who are allegedly predisposed to physics (and therefore can achieve expertise) from the vast majority of people who allegedly lack this predisposition (and therefore can only acquire a basic understanding).

According to the research of Carol S. Dweck, both Wieman's perception and the contrasting perception of many physicists can be integrated into the mindset theory. Dweck describes two mindsets that have a substantial effect on thinking and behaving. The so-called growth mindset is based on the conviction 
that individual potential (regarding intelligence and abilities) can be developed (Dweck, 2006), as expressed by Wieman. In the so-called fixed mindset, the conviction prevails that individual potential (regarding intelligence and abilities) is determined (Dweck, 2006), as expressed by many physicists. Moreover, Dweck emphasizes that both mindsets can be modified. In particular, the possibilities of interventions to induce advancement from a fixed mindset to a growth mindset are explored in her research (Dweck, 2006).

In order to scrutinize the extent to which Dweck's mindset theory can be assigned to high-school students' views of learning physics, an exploratory interview study has been conducted in Germany and Austria.

\section{THEORETICAL BACKGROUND}

\section{Fixed and Growth Mindset}

The term mindset describes predominant patterns of thought and behaviour. In the field of cognitive psychology, mindsets define the sum of cognitive processes activated for a certain task (Gollwitzer, 1990). However, Dweck uses a different definition of mindset which is based on implicit theories of intelligence. This definition refers not only to cognitive processes but especially to beliefs about individual potential. The fixed mindset describes the conviction that an individual's potential (intelligence and abilities) is determined. This mindset supports the objective to prove one's own potential with success. People with fixed mindsets think that the less effort needed to achieve a goal, the higher their personal potential. Success that can only be achieved with great effort is a sign of lacking potential in their view (Mueller \& Dweck, 1998). Therefore, each assessment is deemed to evaluate the person as a whole. In contrast with the fixed mindset, the growth mindset describes the conviction that individual potential can always be developed. This mindset is more conducive to the objective to improve one's own potential with effort. People with growth mindsets think that perseverance is decisive for success, not an innate talent. Therefore, rather than evaluating the person as a whole, an assessment only provides information about the person's current state of development.

In the continuum of implicit theories of intelligence, both mindsets can be understood as two opposite poles (Dweck \& Leggett, 1988). Table 1 compares typical patterns of thought and behaviour resulting from the pure forms of the fixed and the growth mindset (Dweck, 2006). These patterns show that the growth mindset is more beneficial to learning, regardless of the extent to which individual potential is actually determined or developable (you may also want to consult Breker, 2016, a dissertation written in German, for an overview of various scientific positions on this) because the growth mindset improves a person's ability to learn and response to criticism.

Table 1. Comparison of typical patterns of thought and behaviour resulting from the pure forms of the fixed mindset and the growth mindset (based on Dweck, 2006)

\begin{tabular}{ll}
\hline Fixed Mindset & Growth Mindset \\
\hline Challenges are avoided. & $\begin{array}{l}\text { Challenges are valued and accepted. } \\
\text { In case of difficulties, people give up trying. }\end{array}$ \\
$\begin{array}{l}\text { Objective to prove one's own potential with success } \\
\text { (performance goals). }\end{array}$ & $\begin{array}{l}\text { Objective to improve one's own potential with effort (learning } \\
\text { goals). }\end{array}$ \\
$\begin{array}{l}\text { The conviction that innate talent is decisive for success, not } \\
\text { effort. The higher the innate talent, the less effort is needed. }\end{array}$ & $\begin{array}{l}\text { The conviction that perseverance is decisive for success, not an } \\
\text { innate talent. }\end{array}$ \\
$\begin{array}{l}\text { Criticism is related to personality traits and therefore } \\
\text { rejected. }\end{array}$ & $\begin{array}{l}\text { Criticism is related to process characteristics and therefore } \\
\text { accepted. }\end{array}$ \\
$\begin{array}{l}\text { The success of other people threatens one's reputation and } \\
\text { has a depressing effect. }\end{array}$ & $\begin{array}{l}\text { The success of other people promotes one's motivation and has } \\
\text { an inspiring effect. }\end{array}$ \\
\hline
\end{tabular}




\section{Differentiation from (Seemingly) Related Psychological Constructs}

The mindset theory evolved from implicit theories of intelligence and self-theories, with the first major paper of Dweck and Leggett in 1988. (The term "mindset", however, has not been adopted until the publication of the book "Mindset: The new psychology of success" by Dweck in 2006.) According to Dweck and Leggett (1988), mindsets are subject to implicit beliefs about ability: While some people believe ability to be a malleable quality (incremental theory), others believe it to be a fixed trait (entity theory). These two implicit beliefs "represent two different forms of self-concept. Within a generalized entity theory, the self would be conceptualized as a collection of fixed traits that can be measured and evaluated [fixed mindset]. Within an incremental theory, the self would be seen as a system of malleable qualities that is evolving over time through the individual's efforts [growth mindset]." (Dweck \& Leggett, 1988, p. 266).

Figure 1 shows a model suggesting that the goals allied with implicit beliefs "could be seen as the way of generating and maintaining self-esteem within that self-concept" (Dweck \& Leggett, 1988, p. 271). It describes how personality variables can arouse motivational processes, which in turn can evoke response patterns" of cognition, affect, and behavior" (Dweck \& Leggett, 1988, p. 271).

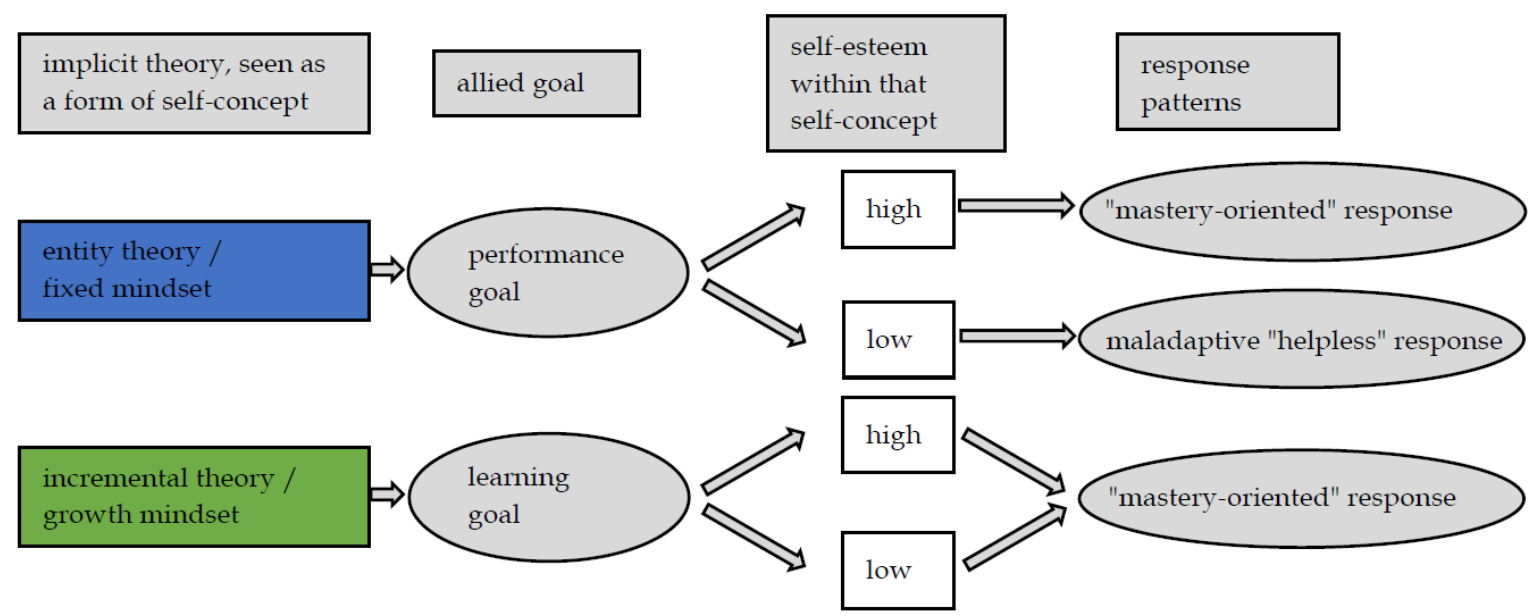

Figure 1. Motivational model according to Dweck \& Leggett (1988) based on Broome (1998)

The authors also examine the model's applicability to an individual's implicit theories of their attributes (Dweck \& Leggett, 1988), in particular to major attributes of the self, such as intellectual competence or social competence. Within this model, mindsets are depicted as the basic principle, that causes attribution schemes (e.g., Abramson et al., 1978; Seligman et al., 1979; Weiner, 1974). However, the mindset approach is distinct from the attributional approach to the extent that the latter "tends to depict particular factors as inherently controllable or uncontrollable, so that ability is considered to be a stable, uncontrollable factor" (Dweck \& Leggett, 1988, p. 269). In contrast, the mindset approach generally regards any factor to be interpretable as stable/uncontrollable or as instable/controllable and it places "controllability in the eyes of the perceiver, for it is these perceptions that will guide the individual's behaviour" (Dweck \& Leggett, 1988, p. 269). Thus, attributing failure to a lack of ability for an entity theorist refers to an immutable factor. A fixed mindset learner pursues performance goals (objective to prove potential with success) and may show maladaptive "helpless" responses. For an incremental theorist it refers to an alterable factor. A growth mindset learner pursues learning goals (objective to improve potential with effort) and therefore can show "mastery-oriented" responses. 


\section{Literature Review}

There are some insights about different percentages of students holding a fixed or growth mindset. In the US, the overall distribution of fixed and growth mindset has been revealed as roughly balanced: About $40 \%$ of the students are allocated to the fixed mindset and $40 \%$ to the growth mindset, while $20 \%$ are without a clear allocation (Dweck, 2008). In some studies, differences are reported in the distribution of mindsets regarding gender. Some data shows that girls are more likely to have a fixed mindset and boys to have a growth mindset (Dweck et al., 1978; Gunderson et al., 2013, in the context of physics see also: Marshman et al., 2017). Among the learners with a fixed mindset, boys are more successful, whereas among the learners with a growth mindset, there is no significant difference in the learning success between boys and girls (Grant \& Dweck, 2003).

Students' mindset is developd during childhood and adolescence, influenced by parents, teachers and the peer group (Cimpian et al., 2007; Kamins \& Dweck, 1999; Mueller \& Dweck, 1998): The praise and criticism that children and adolescents receive can either strengthen a fixed mindset if it relates to the person (e.g., "You must be very talented as your results in the test are so good."), or a growth mindset if it is expressed process-related (e.g. "Great, you have worked so hard and could finally solve that problem."). Consequently, it influences learning behaviour. Undergraduate students with a fixed mindset prefer the so-called "performance goal tasks" that query skills without having to learn new ones (Hong et al., 1999). For them, high brain activity has been observed during quantitative feedback, such as feedback providing information on whether their solution of a certain task is correct or incorrect. Throughout the feedback concerning in-depth information about the task or their solution, there was less brain activity (Mangels et al. 2006). In contrast, undergraduate students with a growth mindset prefer "learning goal tasks" that are aimed at learning new skills (Hong et al., 1999) and high brain activity has been observed during feedback about their solution of a certain task, too. But for them even more brain activity has been observed throughout the feedback concerning in-depth information (Mangels et al., 2006).

The mindset does not only affect learning behaviour but also the learning success (e.g., Blackwell et al., 2007; Costa \& Faria, 2018; Degol et al., 2018; Ortiz Alvarado et al., 2019). As demonstrated in a study by Blackwell et al. in 2007, students who believed that individual potential can be developed, improved their math grades over a period of two years. In contrast, students who believed that individual potential is determined, did not improve their math grades over the same period of time (Blackwell et al., 2007). In a longitudinal study by Degol et al. (2018), the relationship between subjective task values, mindsets and career goals in the STEM subjects was examined. The growth mindset proved to be a predictor of higher subjective task values, which mediates the influence of a growth mindset on STEM career goals: People with a growth mindset appreciate mathematics more, which in turn supports higher STEM career goals (Degol et al., 2018).

As mentioned above, a growth mindset supports academic achievement which is a well-researched field especially concerning STEM subjects. We can only touch on the most important findings here to underline the possibilities of mindset trainings. Cognitive factors as well as affective factors are known to influence learning processes and outcomes. While Hake (2002) found moderate correlations of physics performance with spatial visualization and math skills, Hazari and colleagues (2007) also found that mathematics preparation at school level predicted physics performance at university level. Likewise, Anderton et al. (2017) as well as Nakakoji and Wilson (2014) confirmed the quality of mathematics preparation in high school as predictive for academic performance in STEM courses at university. In another study, Salehi et al. (2019) aimed to predict final exam grades in physics with sociodemographic variables (such as gender, URM status, FG status) and, as they call it, the level of preparation of the students. They found that this level of preparation (consisting of prior-knowledge as measured in SAT or ACT scores and concept inventory tests) having predictive power for exam performance and can explain up to $30 \%$ of the observed variation in exam performance. These described 
predictors for physics achievement are incremental, meaning students are able to develop these by training, and therefore, could also be addressed by a growth mindset training.

Next to cognitive factors, affective factors play an important role in initiating and orienting students' studying (Gungor et al., 2007). For example, attitudes, self-concept, motivation and interest are considered predictors for academic performance (Ardura \& Pérez-Bitrián, 2019; González et al., 2017; Hidi et al., 2004; Marsh \& Martin, 2011; Perkins \& Gratny, 2010; Potvin \& Hasni, 2014). Laukenmann and colleagues (2003) showed that positive emotions are particularly important when acquiring knowledge. Their analysis also indicated that interest supports learning in physics (Laukenmann et al., 2003). Moreover, epistemological beliefs influence learning processes and outcomes (see, e.g., Hammer, 2000; Halloun, 2001; Hofer \& Pintrich, 2016; Lising \& Elby, 2005; May \& Etkina, 2002; Sathopoulou \& Vosniadou, 2007). In this regard, epistemological beliefs are understood not only as learners' conceptions about the methods (e.g., generation and publication of knowledge, social discourse) and the validity of the knowledge, but also as their conceptions about the learnability of the subject. Halloun (2001), for example, captured learnability (item "Science is learnable by anyone willing to make the effort - not just by a few talented people." Halloun, 2001, p. 58) as a cognitive dimension of epistemological beliefs and showed that the notion concerning learnability correlates with final course grades, making another strong argument for a growth mindset training.

With regard to possible trainings to induce advancement from a fixed mindset to a growth mindset, the existing literature seems encouraging. Mindset can be changed intentionally, both by inner monologues and by external influences. Dweck herself puts it as follows: "Mindsets are just beliefs: They're powerful beliefs, but they're just something in your mind, and you can change your mind." (Dweck, 2006, p. 16).

Sometimes even short trainings are sufficient to support a growth mindset: Research at school level proves that mindsets are related to academic success and can be fostered (for an overview see also Yeager \& Walton, 2011) for adolescents at (junior) high school and at college (Aronson et al., 2002; Blackwell et al., 2007; Fink et al., 2018; Good et al., 2003; Yeager \& Dweck, 2012; Yeager et al., 2016, 2019). $\mathrm{Xu}$ and colleagues (2020) assessed the effects of a mindset intervention on secondary school students in a learning environment covering the Doppler effect. "Participants in the growth mindset condition perceived a lower intrinsic load and extraneous load, and performed better on retention and transfer tests." (Xu et al., 2020, p. 2).

A meta-study about a variety of mindset interventions in schools (Sisk et al., 2018) mostly found small effects, that are often larger for students with a low socio-economic status. In another longitudinal study, the influence of a single session of a mindset intervention on beliefs about intelligence of ninth-graders has been examined (DeBacker et al., 2018). The results suggest that this single session can already promote an incremental view of intelligence. Also, the "National Study of Learning Mindsets" by Yeager et al. (2019) shows that a treatment of less than one hour has a significant impact on the learners' grades, especially on the grades of underachieving students in a representative sample for the US. Another result shows that the treatment does not compensate for an unfavourable learning environment. Under this assumption, the intervention would be expected to be particularly effective in such schools where inhibiting norms among the students had previously prevailed. In fact, the intervention proved to be especially effective in schools where growth mindset facilitating norms had already been prevalent (Yeager et al., 2019).

Research on students' mindsets at university level also indicates that it is related to academic success (Costa \& Faria, 2018; Ortiz Alvarado et al., 2019) and can be fostered (Dar-Nimrod \& Heine, 2006). That even a minimally invasive intervention can lead to an improvement in academic performance, especially for those students who belong to an underrepresented ethnical group in their field of study, has been shown by Aguilar et al. (2014) and has been confirmed by Broda et al. (2018). Overall, however, mixed successes from such interventions have been recorded for university students in the literature (McCabe et al., 2020; Sriram, 2013). 
Generally, the importance of mindset trainings is stressed in particular for transitional phases. Recent results from a seventh-grade classroom (Zeeb at al., 2020) suggest mindset interventions when a new school subject (e.g., physics) is being introduced. Likewise, mindset interventions have proven effective as part of a STEM Boot Camp program for incoming freshman at the University of WisconsinWhitewater (Lisberg \& Woods, 2018). Ways to address a growth mindset "in our labs, our classrooms and ourselves" are proposed by Burgasser (2019, p. 1038).

This might be due to the fact that along with transitional phases come challenges in new contexts and for each individual the manifestation of both mindsets may vary depending on the concrete context (Hong et al., 1999; Yeager et al., 2013). For example, a study with students from the US reveals that the proportion of fixed and growth mindsets concerning intelligence changes when the frame of reference shifts between subjects (Dweck, 2008). For the STEM subjects as compared to other subjects, Dweck herself stresses that "we have noted in our research that students tend to have more of a fixed view of math skills than of other intellectual skills" (Dweck, 2008, p. 2).

Thus, it does not seem reasonable to assume that students necessarily have only one domain-general mindset for academic achievement. We must rather assume that students have domain-general as well as domain-specific facets of mindsets (and possibly topic-specific facets of mindsets, too). It has already been shown for programming computers (Scott \& Ghinea, 2014) or playing serious games (Lee et al., 2012) that domain-specific mindsets are better predictors for success.

Likewise, our approach is based on the assumption that mindsets - analogous to related constructs such as the academic self-concept (Marsh, 1990) or epistemological beliefs (Muis et al., 2006) - have domaingeneral as well as domain-specific facets and that these affect learning success at the same level of granularity.

Nevertheless, so far, mindsets have mostly been operationalized as domain-general facets using Dweck's scale (Dweck, 1999) "beliefs about intelligence" (example item: "You have a certain amount of intelligence and really can't do much to change it."), which has sometimes been modified, for example such that "intelligence" has been replaced with "math ability" (see also De Castella \& Byrne, 2015 or Sisk et al., 2018 for an overview of mindset instruments used in several studies). There are only very few studies on domain-specific facets of mindsets, for example on characteristics of language mindsets (Lou \& Noels, 2017), and hence the description, measurement and modification of characteristics of physics mindsets must be considered a research deficit.

\section{OBJECTIVE}

Since it could be one important (but so far largely neglected) factor to consider not only domain-general, but also domain-specific facets of mindsets, there are numerous relevant questions which intersect with the interests of physics education researchers. As a first step, this pioneering interview study aims to clarify whether the mindset theory can be applied to students' beliefs about learning physics by investigating the following research questions:

(F1) Can the fixed mindset and the growth mindset (as described by Dweck) be identified in students' beliefs about physics?

(F2) Do only the pure forms of fixed mindset and growth mindset occur or are there mixed forms, too?

(F3) On the basis of which characteristics is it possible to assign the students to these forms of mindsets?

(F4) Are there mindset aspects which are distinctive for the domain of physics? 


\section{DESIGN AND METHODS}

\section{Sample}

To investigate these questions, an exploratory interview study has been conducted with $\mathrm{N}=51$ students (27 female, 24 male) from Germany and Austria. In the Austrian sample, 30 students in grades 10, 11 and 12 from two different types of upper schools in the region of Ried and Braunau have been interviewed (19 students attending BAfEP, a pedagogical institute, and 11 students attending HTL, a technical institute). In the German sample, 21 students in grade 9 from different high schools in the Rhine-Main region (Frankfurt, Darmstadt, Hanau) have been interviewed.

Participation was voluntary: The students were informed about the interviews beforehand. Those who were willing to involve were sent an information letter with a declaration of consent for their parents or legal guardians. There was no targeted pre-selection of the interviewees in terms of their gender, performance, or other characteristics.

\section{Setting}

The decision was taken to conduct interviews, as this research method allows high adaptability and therefore seems appropriate to assess an individual's beliefs for characterizing mindsets.

The interviews lasted an average of about 20 minutes and have been conducted and recorded at the schools of the interviewees. A guideline has been used to structure the process. The same guideline was used for all interviews and the questions of the guideline were posed to all interviewees to ensure a common database for the analysis (Krüger et al., 2014). In-between these questions, however, passages of the individual interviews may differ from the guideline.

The guideline has been organized as follows: Questions to open the interview are directly related to the learners (for example: "How do you rate your own performance in physics? Why is that, what do you think?"). Further questions are asked about what the learners expect in physics in the future (for example: "Suppose you had to sit an exam on the material that has been taught in physics over the past year. Do you think you could get the top grade? How?"). Hereafter, the frame of reference for these questions is extended to other students and to other subjects (for example: "Does this apply to everyone in your class? Does this apply to every subject?"). Finally, students are reminded of successful physicists like Albert Einstein. They are asked about why they think he could achieve so much (for example: "One of the most famous physicists was Albert Einstein. Why do you think he was so successful in this area?"). If it has not been mentioned by the interviewees in the course of the interview, the guideline concludes with questions about the learner's mindset (for example: "Do you think there is such a thing as an innate talent for physics?").

\section{Implementation}

The implementation has been a three-stage process: Three cohorts of students have been interviewed as part of three degree-projects of pre-service teachers at university in the field of physics education research. The first cohort has been interviewed in upper Austria in June/July 2016 (Schwamberger, 2017). This was supplemented by the second cohort from the Rhine-Main region in June/July 2017 (Goldhorn, 2017). Both surveys have been analysed using qualitative content analysis (Mayring, 2015) and for each survey a category system has been developed independently. Hereafter, these two category systems have been compared and combined into the final category system. This has been used to (re-)analyse the first and second cohort as well as the newly collected third cohort from the Rhine-Main region in March 2018 (Brück, 2018), completing the sample. 


\section{Evaluation}

The evaluation procedure follows qualitative content analysis by Mayring (2015) and is carried out in three steps: 1. Data collection (conducting the interviews), 2. Data processing (transcribing, paraphrasing, and generalizing the interviews), 3. Data evaluation (inductive category formation).

All statements were given with a reference to the location of the quote in the data (Mayring, 2015). For setting up the categories, statements with similar meanings were bundled into units from which the various categories could be derived. These were divided into main categories and subcategories.

After that, in order to refer to Dweck's mindset theory, the categories were assigned to the fixed mindset or the growth mindset as far as possible. Finally, each interview has been summarized again considering occurring categories to characterize the learner's mindset.

For this, a comparison of the mere numbers of categories in both mindsets was usually not sufficient. Rather, contextual references had to be taken into account to weigh up the categories in both mindsets against each other.

\section{RESULTS}

\section{Coding Scheme}

Seven main categories were identified from the interviews, each of them is divided into subcategories. These are presented with examples for students' statements in Table $2 .{ }^{1}$

Table 2. Categories $K 1$ to $K 7$ and subcategories with a typical quote (including reference to the according interview) ('GM growth mindset', 'FM fixed mindset' or 'no assignment')

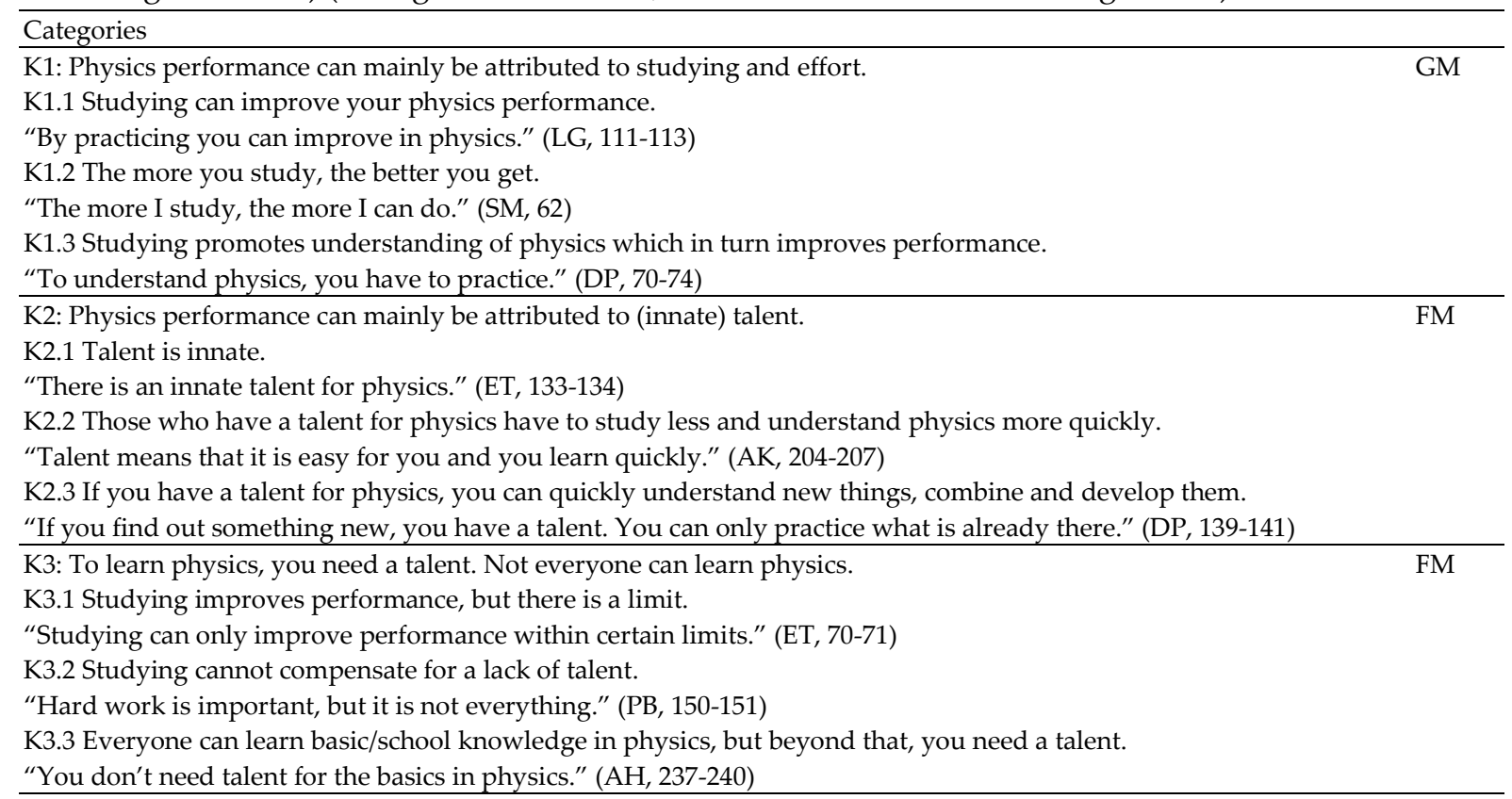

\footnotetext{
${ }^{1}$ As the interviews were evaluated in German language, a translation of the derived coding scheme (categories and subcategories with typical quotes) was necessary for this article. Subsequently, this translation was checked by an English native speaker. In all cases where unclear or ambiguous connotations of formulations were identified, we were able to arrive at a discursive agreement and in our opinion, this has largely eliminated possible misinterpretations.
} 
Table 2 (continued). Categories K1 to K7 and subcategories with a typical quote (including reference to the according interview) ('GM growth mindset', 'FM fixed mindset' or 'no assignment')

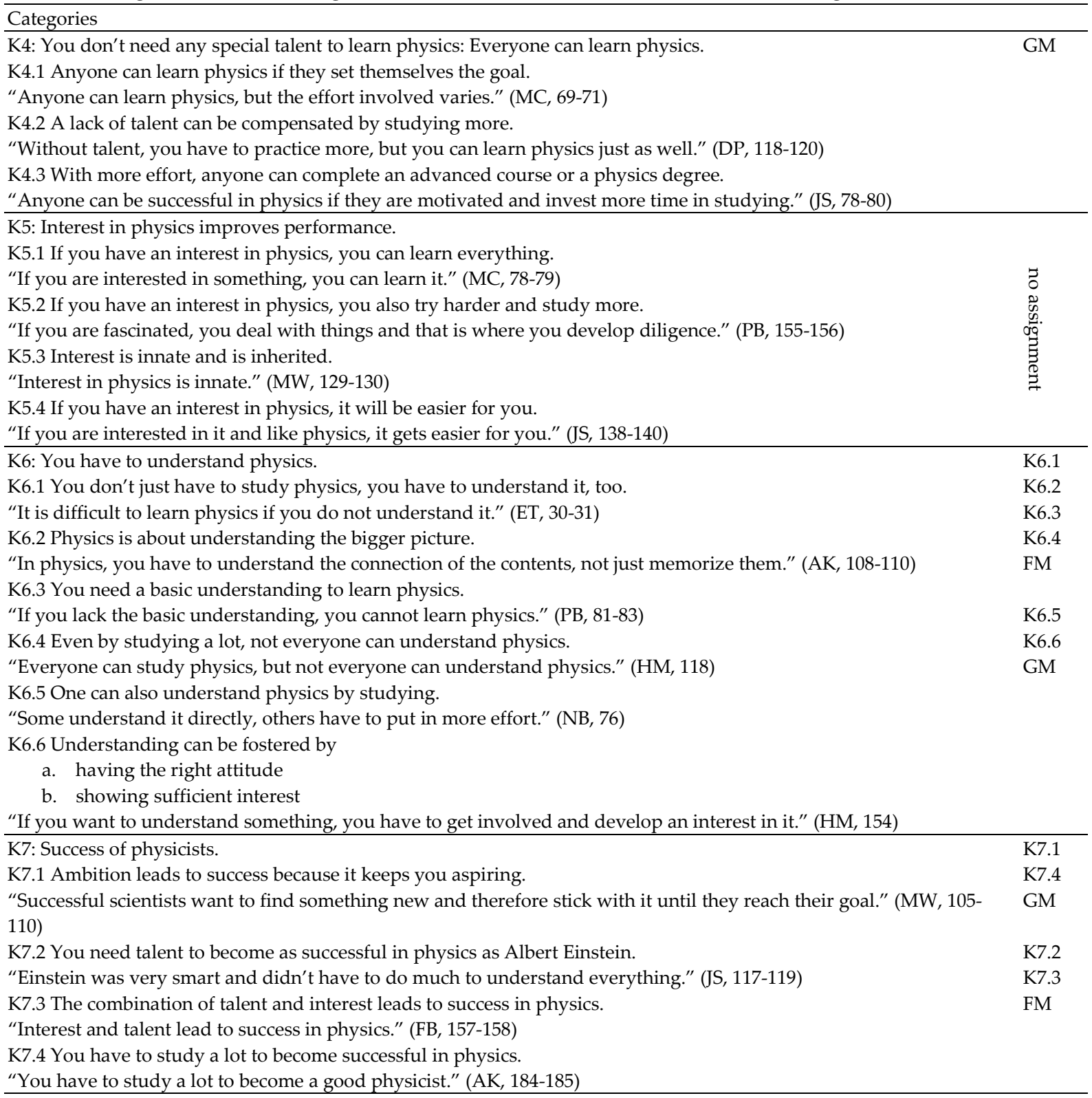

A subsample of $10 \%$ of the interviews (five interviews) has been used for a reliability check. These interviews have been analysed by a second person based on the final category system, with 51 matches in a total of 66 coded text passages. This reliability of $87 \%$ is considered good according to Holsti (1969).

The main categories K1-K4 represent statements of the mindset theory as described in literature, therefore the categories can be assigned to either the fixed or the growth mindset. The main categories $\mathrm{K} 6$ and $\mathrm{K} 7$ each contain subcategories representing both, the fixed and the growth mindset. The main category $\mathrm{K} 5$ is about interest, but since there was no clear definition of the term interest given during the interviews, students' conception concerning the fixedness or malleability of interest in physics is unclear and for this reason no definite assignment of the subcategories to one of the mindsets can be made.

\section{Case Study: Fixed Mindset}

In order to illustrate the coding scheme and the mindset characteristics of physics learners, the statements of a student who has been assigned having a fixed mindset are presented below. 
At the time of the interview, student PB (male) attended the 9th grade at high school. He answers the question of whether he likes physics: "I find the lessons very interesting [...] but it doesn't light me on fire. Maybe, I lack the talent or something, but that's rather something that runs in the family." (lines 10-13) In the course of the interview, he also explains what exactly he means by the term talent: Having no talent "means that I partially lack the basic understanding, and - above all - that I do not have the talent to acquire and to maintain the basics." (lines 34-35) These two statements already contain essential aspects of the fixed mindset, the belief in innate talent, which is necessary to become successful in physics. Regarding his current level of performance in physics, PB says: "Well, if I would hang in there now, I could still get a good grade." In his opinion, effort can improve performance, but only within his limits, as he explains later: "With regard to the advanced course, I don't think that everyone could do it. We have talented people who plan to study physics and [for them] I don't see any problems at all of course they can take that as an advanced course. [...] But there are also [us] like-minded people [...] who did not choose this as an advanced course, and this might be wise." (lines 86-93).

Table 3 shows the statements found in PB's interview and their assignment to the category system. Even though there are statements assigned to growth mindset categories (for example: "If I am diligent in the field, I can maintain or improve my performance." lines 75-76), PB shows a fixed mindset in almost all physics-related statements. Finally, a comparison of the counts of categories in both mindsets supplemented with contextual references to weigh up the categories against each other reveals that $\mathrm{PB}$ should be characterized a fixed mindset learner in physics.

Table 3. Statements that were found in PB's interview and their assignment to the category system (GM growth mindset, FM fixed mindset)

\begin{tabular}{|c|c|c|}
\hline Statement & Category & Mindset \\
\hline $\begin{array}{l}\text { If I am diligent in the field, I can maintain or improve my } \\
\text { performance. (75-76) }\end{array}$ & $\begin{array}{l}\text { K1.1: Studying can improve your physics } \\
\text { performance. }\end{array}$ & GM \\
\hline Talent for physics runs in the family. (13) & K2.1: Talent is innate. & FM \\
\hline $\begin{array}{l}\text { Being diligent and studying is rather unimportant if you have } \\
\text { talent. (127-129) }\end{array}$ & $\begin{array}{l}\text { K2.2: Those who have a talent for physics have to } \\
\text { study less and understand physics more quickly. }\end{array}$ & FM \\
\hline Diligence is not everything, but diligence is a lot. (150-151) & $\begin{array}{l}\text { K3.2: Studying cannot compensate for a lack of } \\
\text { talent. }\end{array}$ & FM \\
\hline $\begin{array}{l}\text { I do not have the talent to acquire and maintain the basic } \\
\text { understanding. (34-35) }\end{array}$ & $\begin{array}{l}\text { K3.3: Everyone can learn basic/school knowledge in } \\
\text { physics, but beyond that, you need a talent. }\end{array}$ & FM \\
\hline $\begin{array}{l}\text { Due to a lack of understanding, it is difficult to follow the } \\
\text { lesson and learn. }(17-21)\end{array}$ & $\begin{array}{l}\text { K6.1: You don't just have to study physics, you have } \\
\text { to understand it, too. }\end{array}$ & FM \\
\hline $\begin{array}{l}\text { A physics advanced course is difficult to complete because } \\
\text { basic understanding is a prerequisite. }(81-83)\end{array}$ & $\begin{array}{l}\text { K6.3: You need a basic understanding to learn } \\
\text { physics. }\end{array}$ & FM \\
\hline $\begin{array}{l}\text { Einstein had the talent, what it takes }[\ldots] \text { and I think that's the } \\
\text { point of his genius. (124-126) }\end{array}$ & $\begin{array}{l}\text { K7.2: You need talent to become as successful in } \\
\text { physics as Albert Einstein. }\end{array}$ & FM \\
\hline
\end{tabular}

\section{Case Study: Growth Mindset}

As a contrasting example, the statements of another student who has been assigned having a growth mindset are presented below.

The student FB (female) also attended the 9th grade at high school. She rejects the concept of talent but defines interest in a similar way: "There is definitely the innate thing that you are interested in physics. But a gift for it - I don't think so." (lines 144-146) According to her definition, interest does not determine success in physics, but promotes it through increased engagement with the subject. FB says: "If you are interested in something, it is not studying, but it is discovering out of interest." (lines 122-124) She has this conviction both for learning physics at school and at university. What interest does not mean for her, is a faster or easier learning success. FB is of the opinion that everyone can learn physics. When it's 
more difficult, she will just cram more or need more time, which also applies to all of her classmates and every level of difficulty (e.g., advanced courses).

Table 4 summarizes the statements found in FB's interview and their assignment to the category system. Again, although there are statements assigned to fixed mindset categories (for example: "One would have to combine the talent for logical thinking with interest in order to be very good or excellent in physics." lines 157-158), FB has a growth mindset in almost all physics-related statements. A comparison of the counts of categories in both mindsets and the contextual references to weigh up the categories against each other reveals that therefore FB should be characterized a growth mindset learner in physics.

Table 4. Statements that were found in FB's interview and their assignment to the category system (GM growth mindset, FM fixed mindset)

\begin{tabular}{|c|c|c|}
\hline Statement & Category & Mindset \\
\hline $\begin{array}{l}\text { [To get better] I would pay more attention in class and then look } \\
\text { at things more often after school. (62-63) }\end{array}$ & $\begin{array}{l}\text { K1.1: Studying can improve your physics } \\
\text { performance. }\end{array}$ & GM \\
\hline $\begin{array}{l}\text { When it's more difficult, I just cram more or take more time. } \\
(100-102)\end{array}$ & $\begin{array}{l}\text { K4.1: Anyone can learn physics if they set } \\
\text { themselves the goal. }\end{array}$ & GM \\
\hline $\begin{array}{l}\text { [Understanding means] I know what the teacher says and how it } \\
\text { relates. (34) }\end{array}$ & $\begin{array}{l}\text { K6.2: Physics is about understanding the } \\
\text { bigger picture. }\end{array}$ & FM \\
\hline $\begin{array}{l}\text { [Einstein was so successful in physics] because he found out a lot } \\
\text { of new things and also had an interest in finding out and } \\
\text { knowing the reason why things happen. (113-115) }\end{array}$ & $\begin{array}{l}\text { K7.1: Ambition leads to success because it } \\
\text { keeps you aspiring. }\end{array}$ & GM \\
\hline $\begin{array}{l}\text { Certainly, there were places where it was not so easy for him } \\
\text { [Einstein] because he may not have made any progress or } \\
\text { something. (126-127) }\end{array}$ & $\begin{array}{l}\text { K7.1: Ambition leads to success because it } \\
\text { keeps you aspiring. }\end{array}$ & GM \\
\hline $\begin{array}{l}\text { One would have to combine the talent for logical thinking with } \\
\text { interest in order to be very good or excellent in physics. (157-158) }\end{array}$ & $\begin{array}{l}\text { K7.3: The combination of talent and interest } \\
\text { leads to success in physics. }\end{array}$ & $\mathrm{FM}$ \\
\hline
\end{tabular}

\section{Overview of the Individual Cases}

As already observed in the case studies, the individual interviews usually contain statements from categories of the fixed mindset in addition to statements from categories of the growth mindset. In order to properly characterize the learner's mindset, contextual references had been taken into account to weigh up the categories in both mindsets. For example, codes in categories K1 to K4, that are pure categories, were given more weight than codes in the mixed category K6. K6 contains the concept, that a basic understanding is necessary for learning physics. How the interviewed students define this basic understanding differs: $\mathrm{PB}$ of the fixed mindset case study describes this basic understanding regarding the physics curriculum, one needs the basic knowledge in physics of middle school for being successful at an advanced level physics course. But other students describe the concept of basic understanding more fundamental as logical thinking or science thinking, as something innate. Due to these variable interpretations of basic understanding and the fact, that some students use it as an argument for their fixed view and others argue with it for an incremental view, students' statements in K6 were were given less weight in comparison with statements from the categories $\mathrm{K} 1$ to $\mathrm{K} 4$.

Category K7 was given less weight because it relates to scientists and many of the interviewed students differentiated between learning physics as a school subject and physics as a science. Some students explained that while one would need a certain giftedness to become a physicist, everyone could still learn physics at school. Some students even considered their teacher's knowledge in physics in between the school level and the science level. This differentiation of physics as a school subject and physics as a science should definitely be examined further. But since this study cannot provide such insights, and with the focus of this study lying on students' beliefs about learning physics at school, category K7 was weighted less for the characterization of mindsets in those cases where students' statements in K7 were 
contradictory to their statements in other categories (e. g., fixed mindset statements in K7 with more growth mindset statement in other categories). ${ }^{2}$

Codes in category $\mathrm{K} 5$ were ignored for the characterization of mindsets since there was no clear definition of the term interest given during the interviews and therefore no definite assignment of the subcategories to one of the mindsets has been made.

Figure 2 shows the results of the characterization of the learners' mindsets. Each student was characterized as one of the mindset types (either pure or mixed) based on the statements that fit the described (sub-)categories. If there are several statements belonging to the fixed mindset and several statements belonging to the growth mindset, the student was assigned to a mixed mindset type. Two of those mixed mindsets were defined: Those with a tendency to the fixed mindset and those with a tendency to the growth mindset. As the mixed mindset group is so broad, this further differentiation is considered suitable for the data. Moreover, this differentiation serves to facilitate traceability of the interpretation (thereby more heavily weighted codes can be identified).

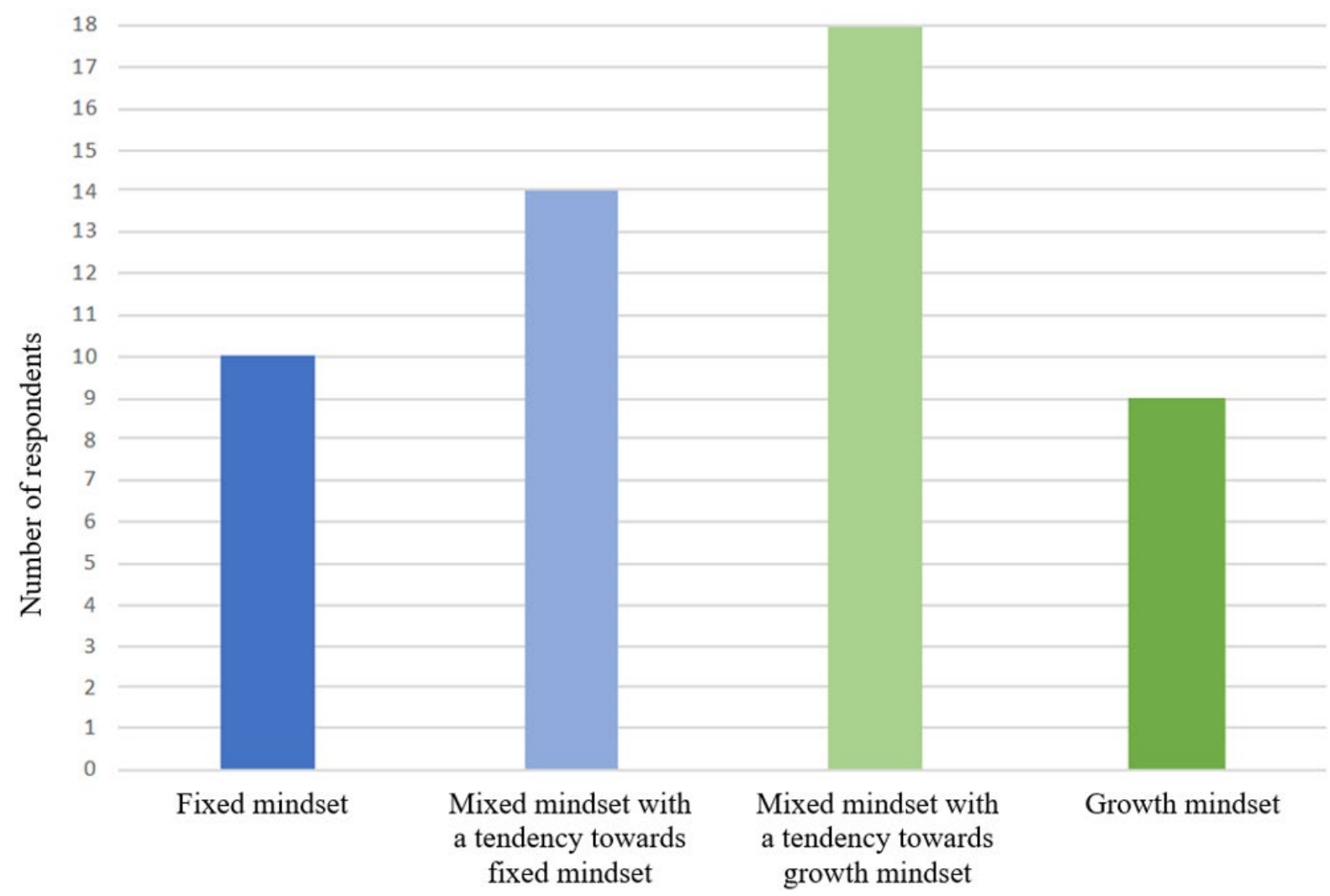

Figure 2. Assignment of the $\mathrm{N}=51$ learners to the four mindset types fixed mindset, mixed mindset with a tendency to fixed mindset, mixed mindset with a tendency to growth mindset and growth mindset

\section{DISCUSSION}

The research questions are answered as follows.

(F1) Can the fixed mindset and the growth mindset (as described by Dweck) be identified in students' beliefs about physics? Our results confirm the impression that we have already received when conducting the interviews: Almost all students have very clear beliefs about their own capability in physics. In each interview, several learner statements were found that could be assigned to categories of either the fixed

${ }^{2}$ Otherwise, there would be slightly more students being assigned to the fixed mindset, who are now being assigned to the mixed mindset. 
or the growth mindset. With these statements supplemented by contextual references, the learners' mindsets could be characterized. The evidence presented in this paper provides strong support that in students' beliefs about physics Dweck's definition of mindsets can be identified.

(F2) Do only the pure forms of fixed mindset and growth mindset occur or are there mixed forms, too? Almost $40 \%$ of the interviewees clearly showed a fixed or growth mindset (roughly $20 \%$ for each) according to our analysis. The remaining $60 \%$ of the interviewees have mixed concepts. In some interviews, the respondents distinguish between "physics as a school subject" and "physics as a professional career", e.g., that talent is assumed to be not required for students but for scientists. In other interviews, they counterbalance talent and effort, e.g., they argue that with talent less effort is needed to meet standard requirements, but even with talent you still have to put in effort to achieve excellent performance. Some of the respondents totally rejected the concept of talent but used other terms with a similar meaning (e.g., gift). Therefore, in addition to the fixed and the growth mindset, two mixed mindsets were defined, one with a tendency towards a fixed mindset and one with a tendency towards a growth mindset. In the future, further surveys will be necessary to check whether this distinction in four types of mindset is reasonable, or whether a distinction in three types of mindset (two pure forms and only one mixed concept) would be more suitable.

(F3) On the basis of which characteristics is it possible to assign the students to these forms of mindsets? Seven main categories were found (see Table 2) from which five characteristics can be derived that are key to assigning students to the different forms of mindsets:

- Concept of talent: Is a special talent necessary for physics (K3) and can performance be attributed to it (K2)?

- Learning effort: Is no special talent necessary for physics (K4) and can performance be attributed to learning effort (K1)?

- Interest: Is interest important for learning physics? (K5)

- Understanding: Is understanding important for learning physics (K6)

- Success: How can the success of physicists be justified? (K7)

(F4) Are there mindset aspects which are distinctive for the domain of physics? While the characteristics concept of talent and learning effort correlate with the general theory, other characteristics like understanding and interest emerged in the current interview study on students' mindsets in physics. To our knowledge, these have not been reported as key issues for mindsets yet. Moreover, the characteristic success shows that some students differentiate between "physics as a school subject" and "physics as a professional career". Therefore, in subsequent surveys about mindsets in physics the respective frame of reference (school subject or professional career) must be clearly defined for the respondents.

In this study, students' beliefs about learning physics at school have been addressed. With regard to the characteristic understanding, some subcategories indicate a growth mindset (e.g., "One can also understand physics by studying."), while others indicate a fixed mindset (e.g. "Even by studying a lot, not everyone can understand physics."). Likewise, with regard to the characteristic interest, there was no agreement with the interviewed students about how the term interest is understood. Therefore, it is unclear, whether it indicates a growth mindset or a fixed mindset and the codes of this category were left aside for the characterization of the mindsets. Individual interest (as a personal characteristic) and interestingness of a situation are predictors for higher levels of motivation (Krapp, 1992), for increased attentiveness, better learning processed and outcomes (Schiefele \& Wild, 1994). Some of the students' statements about interest seem to follow these results, e.g., "If you have an interest in physics, you can learn everything". With regard to the mindset theory those statements could be interpreted as: "If you choose physics, you can learn everything" and therefore suggesting a growth mindset. At the same time, some students use the term interest as almost synonymous with the talent for physics (e.g., "If you 
have an interest in physics, it will be easier for you.", that is, "If you have a talent for physics, it will be easier for you") corresponding to a fixed mindset. Furthermore, it is also striking that - on the one hand - interest is conducive for understanding in the opinion of some respondents. On the other hand, the opinion that interest might be fostered by studying has not been expressed by any of the respondents. In a study of O'Keefe et al. (2018) the fixed beliefs versus the malleable beliefs of interest were explored. They found both fixed and growth beliefs of interest and their study shows a causal effect: "Compared with a growth theory, a fixed theory of interest reduces people's interest in a topic outside their established area of interest." (O'Keefe et al., 2018, p. 7). If this will be confirmed in further studies, that students sometimes relate interest to a fixed mindset (e.g., "interest is innate and is inherited"), it would open totally new perspectives on this field of research. Which consequences would have to be drawn with regard to support programs for interest in physics, would a considerable number of students take the view that "interest is innate and is inherited"?

However, due to the limited sample, quantitative statements about students' mindset in physics cannot be obtained from our study. Also, the influence of individual variables on the development of mindsets cannot be derived either. Theoretically, there are several affecting factors that have to be discussed. For example, gender-specific manifestations of mindsets are conceivable and will have to be examined in the future. It has also been shown that parents' and teachers' praise and criticism shapes children's mindsets (Cimpian et al., 2007; Kamins \& Dweck, 1999; Mueller \& Dweck, 1998). With regard to physics, it is still necessary to determine to which extent these factors affect mindsets and whether it depends on other factors, such as the age of children and adolescents or their experiences in physics classrooms.

\section{Summary}

In summary, according to the results of our survey, it is possible to apply the mindset theory according to Dweck to students' beliefs about learning physics. The learners' mindsets are characterized into four types, two pure types of fixed mindset and growth mindset, as well as two mixed types with a tendency to either of the pure types.

Furthermore, five characteristics for the differentiation between fixed and growth mindsets in physics were derived. The comparison of these characteristics with the mindset theory shows that domaingeneral aspects (concept of talent and learning effort) could be confirmed, while at the same time possible domain-specific aspects (understanding and interest) emerged that undoubtedly require further examination.

\section{Outlook}

Even though there are widely used instruments for querying domain-general mindsets (e.g., Dweck \& Molden, 2005), there are no instruments available for possible domain-specific mindsets in physics. Therefore, our results of the presented exploratory interview study have created a valuable foundation to devise scales for quantitative studies. On that basis we have taken first steps in this direction in our research group (Goldhorn et al., 2020). As a next step, in order to ensure that these scales meet the recognized psychometric quality criteria for measuring psychological constructs (Döring \& Bortz, 2016), they will be empirically tested. In terms of reliability the internal consistency will be checked. In terms of validity, among other things, related (e.g., motivational) constructs should have a high correlation with mindsets (convergent validity) and unrelated (e.g., cognitive) constructs should correlate only weakly with mindsets (discriminative validity) (Buehl et al., 2002; Cook et al., 2017; De Castella \& Byrne, 2015; Schmidt et al., 2019; Zhu et al., 2020). In addition, a relationship between mindsets and indicators for performance at a similar level of granularity should be explored as an indicator for criterion validity of mindsets. For example, subject-specific mindsets should be related to the subject grades (vgl. Lee et al., 2012; Schmidt et al., 2019; Scott \& Ghinea, 2014; Zhu et al., 2020). 
Furthermore, it will be explored to what extent mindsets predict learning success better than other (motivational or cognitive) constructs and to what extent clusters allow conclusions to be drawn about the characteristics and the interaction of domain-general and domain-specific facets of mindsets.

Only with research scales that allow for quantitative studies with larger sample sizes, our medium-term project goal can be tackled, which is to develop and evaluate intervention programs that promote advancement from a physics-specific fixed mindset to a growth mindset.

Author contributions: All authors were involved in concept, design, collection of data, interpretation, writing, and critically revising the article. All authors approve final version of the article.

Funding: The authors received no financial support for the research and/or authorship of this article.

Declaration of interest: Authors declare no competing interest.

Acknowledgements: Our thanks go to all students involved in the study, whose readiness to participate in the interviews made the results possible. We also thank Teresa Maria Schwamberger and Jonas Brück for their contribution.

Data availability: Data generated or analysed during this study are available from the authors on request.

\section{REFERENCES}

Abramson, L. Y., Metalsky, G. I., \& Alloy, L. B. (1989). Hopelessness depression: A theory-based subtype of depression. Psychological Review, 96(2), 358-372. https://doi.org/10.1037/0033-295X.96.2.358

Abramson, L. Y., Seligman, M. E., \& Teasdale, J. D. (1978). Learned Helplessness in Humans: Critique and Reformulation. Journal of Abnormal Psychology, 87(1), 49-74. https://doi.org/10.1037/0021-843X.87.1.49

Aguilar, L., Walton, G., \& Wieman, C. (2014). Psychological Insights for Improved Physics Teaching. Physics Today, 67(5), 43-49. https://doi.org/10.1063/PT.3.2383

Anderton R., Hine, G., \& Joyce, C. (2017). Secondary School Mathematics and Science Matters: Academic Performance for Secondary Students Transitioning into University Allied Health and Science Courses. International Journal of Innovation in Science and Mathematics Education, 25(1), 34-47.

Ardura, D., \& Pérez-Bitrián, A. (2019). Motivational Pathways towards Academic Achievement in Physics \& Chemistry: A Comparison between Students who Opt out and those who Persist. Chemistry Education Research and Practice, 20(3), 618632. https://doi.org/10.1039/C9RP00073A

Aronson, J., Fried, C. B., \& Good, C. (2002). Reducing the Effects of Stereotype Threat on African American College Students by Shaping Theories of Intelligence. Journal of Experimental Social Psychology, 38, 113-125. https://doi.org/10.1006/jesp.2001.1491

Blackwell, L. S., Trzesniewski, K. H., \& Dweck, C. S. (2007). Implicit Theories of Intelligence Predict Achievement Across an Adolescent Transition: A Longitudinal Study and an Intervention. Child Development, 78(1), 246-263. https://doi.org/10.1111/j.1467-8624.2007.00995.x

Breker, T. (2016). Fähigkeitsselbstkonzept, Selbstwirksamkeit \& Mindset - Wie können Lehrkräfte Erkenntnisse aus der Sozial-KognitivenPsychologie nutzen, um die Potenzialentfaltung von Schülerinnen und Schülern zu fördern? [Ability Self-Concept, Self-Efficacy $\mathcal{E}$ Mindset - How Can Teachers Use Findings from Social Cognitive Psychology to Promote the Development of Potential in Students?] [Doctoral thesis, Europa-Universität Viadrina Frankfurt]. https://opus4.kobv.de/opus4euv/frontdoor/index/index/docId/209

Broda, M., Yun, J., Schneider, B., Yeager, D. S., Walton, G. M., \& Diemer, M. (2018). Reducing Inequality in Academic Success for Incoming College Students: A Randomized Trial of Growth Mindset and Belonging Interventions. Journal of Research on Educational Effectiveness, 11(3), 317-338. https://doi.org/10.1080/19345747.2018.1429037

Broome, P. (1998) Implizite Begabungstheorien und erlernte Hilflosigkeit [Implicit Theories of Talent and Learned Helplessness]. Peter Lang.

Brück, J. (2018). "Physik muss man nicht nur lernen, sondern auch verstehen!" - Fachspezifische Mindsets von Schülerinnen und Schülern. [You don't just Have to Learn Physics, You also Have to Understand It! "- Subject-specific mindsets of students] [Unpublished Thesis, TU Darmstadt].

Buehl, M. M., Alexander, P. A., \& Murphy, P. K. (2002). Beliefs about Schooled Knowledge: Domain Specific or Domain General? Contemporary Educational Psychology, 27, 415-449. https://doi.org/10.1006/ceps.2001.1103

Burgasser, A. J. (2019). Why I teach Growth Mindset. Nature Astronomy, 3, 1038-1040. https://doi.org/10.1038/s41550-019-0940-7

Cimpian, A., Arce, H.-M. C., Markman, E. M., \& Dweck, C. S. (2007). Subtle Linguistic Cues Affect Children's Motivation. Psychological Science, 18(4), 314-316. https://doi.org/10.1111/j.1467-9280.2007.01896.x

Cook, D. A., Castillo, R. M., Gas, B., \& Artino, A. R. (2017). Measuring Achievement Goal Motivation, Mindsets and Cognitive Load: Validation of three Instruments' Scores. Medical Education, 51(10), 1061-1074. https://doi.org/10.1111/medu.13405

Costa, A. \& Faria, L. (2018). Implicit Theories of Intelligence and Academic Achievement: A Meta-Analytic Review. Frontiers in Psychology, 9, 829. https://doi.org/10.3389/fpsyg.2018.00829 
Dar-Nimrod, I., \& Heine, S. J. (2006). Exposure to Scientific Theories Affects Women's Math Performance. Science, 314(5798), 435435. https://doi.org/10.1126/science. 1131100

De Castella, K., \& Byrne, D. (2015). My Intelligence May Be More Malleable Than Yours: The Revised Implicit Theories of Intelligence (Self-theory) Scale Is a Better Predictor of Achievement, Motivation, and Student Disengagement. European Journal of Psychology of Education, 30(3), 245-267. https://doi.org/10.1007/s10212-015-0244-y

DeBacker, T. K., Heddy, B. C., Kershen, J. L., Crowson, H. M., Looney, K., \& Goldman, J. A. (2018). Effects of a One-Shot Growth Mindset Intervention on Beliefs about Intelligence and Achievement Goals. Educational Psychology, 38(6), 711-733. https://doi.org/10.1080/01443410.2018.1426833

Degol, J. L., Wang, M.-T., Zhang, Y., \& Allerton, J. (2018). Do Growth Mindsets in Math Benefit Females? Identifying Pathways between Gender, Mindset, and Motivation. Journal of Youth and Adolescence, 47(5), 976-990. https://doi.org/ 10.1007/s10964017-0739-8

Döring, N., \& Bortz, J. (2016). Forschungsmethoden und Evaluation in den Sozial- und Humanwissenschaften [Research Methods and Evaluation in the Social and Human Sciences]. Springer. https://doi.org/10.1007/978-3-642-41089-5

Dweck, C. (2008). Mindsets and Math/Science Achievement. Carnegie Corporation of New York, Institute for Advanced Study, Commission on Mathematics and Science Education. https://www.growthmindsetmaths.com/uploads/2/3/7/7/23776169/ mindset_and_math_science_achievement_-_nov_2013.pdf

Dweck, C. S. \& Molden, D. C. (2005). Self Theories: Their Impact on Competence Motivation and Acquisition. In A. J. Elliot and C. S. Dweck (Eds.), Handbook of Competence and Motivation (pp. 122-140). The Guilford Press.

Dweck, C. S. (1999). Essays in Social Psychology. Self-theories: Their Role in Motivation, Personality, and Development. Psychology Press.

Dweck, C. S. (2006). Mindset: The new Psychology of Success. Random House.

Dweck, C. S. and Leggett, E. L. (1988). A Social-Cognitive Approach to Motivation and Personality. Psychological Review, 95(2), 256-273. https://doi.org/10.1037/0033-295X.95.2.256

Dweck, C. S., Davidson, W., Nelson, S., \& Enna, B. (1978). Sex Differences in Learned Helplessness: II. The Contingencies of Evaluative Feedback in the Classroom and III. An Experimental Analysis. Developmental Psychology, 14(3), 268-276. https://doi.org/10.1037/0012-1649.14.3.268

Fink A., Cahill, M. J., McDaniel, M. A., Hoffman, A., \& Frey, R. F. (2018). Improving General Chemistry Performance through a Growth Mindset Intervention: Selective Effects on Underrepresented Minorities. Chemistry Education Research and Practice, 19, 783-806. https://doi.org/10.1039/C7RP00244K

Goldhorn, L. (2017). Mindsets von Schülerinnen und Schülern im Fach Physik - Eine Interviewstudie [Students' Mindsets in the Subject of Physics - An Interview Study] [Unpublished Thesis, TU Darmstadt].

Goldhorn, L., Wilhelm, T., Spatz, V., \& Rehberg, J. (2020). Fixed und Growth Mindset: Selbstbilder von Schüler*innen in Physik [Fixed and Growth Mindsets: Self-Images of Students in Physics] PhyDid B - Didaktik der Physik - Beiträge zur DPGFrühjahrstagung, 187-191. http://www.phydid.de/index.php/phydid-b/article/view/1030/1126

Gollwitzer, P. M. (1990). Action Phases and Mindsets. In E. T. Higgins \& R. M. Sorrentino (Eds.), Handbook of Motivation and Cognition: Foundations of Social Behavior (pp. 53-92). Guilford Press.

González, A., Fernández, M. V. C., \& Paoloni, P. V. (2017). Hope and Anxiety in Physics Class: Exploring their Motivational Antecedents and Influence on Metacognition and Performance. Journal of Research in Science Teaching, 54(5), 558-585. https://doi.org/10.1002/tea.21377

Good, C., Aronson, J., \& Inzlicht, M. (2003). Improving Adolescents' Standardized Test Performance: An Intervention to Reduce the Effects of Stereotype Threat. Applied Developmental Psychology, 24, 645-662. https://doi.org/10.1016/j.appdev.2003.09.002

Grant, H., \& Dweck, C. S. (2003). Clarifying Achievement Goals and Their Impact. Journal of Personality and Social Psychology, 85(3), 541-553. https://doi.org/10.1037/0022-3514.85.3.541

Gunderson, E. A., Gripshover, S. J., Romero, C., Dweck, C. S., Goldin-Meadow, S., \& Levine, S. C. (2013). Parent Praise to 1- to 3Year-Olds Predicts Children's Motivational Frameworks 5 Years Later. Child Development, 84(5), 1526-1541. https://doi.org/ 10.1111/cdev.12064

Gungor, A., Eryılmaz, A., \& Fakıoglu, T. (2007). The Relationship of Freshmen's Physics Achievement and their Related Affective Characteristics. Journal of Research in Science Teaching, 44. 1036-1056. https://doi.org/10.1002/tea.20200

Hake, R. R. (2002). Relationship of Individual Student Normalized Learning Gains in Mechanics with Gender, High-School Physics, and Pretest Scores on Mathematics and Spatial Visualization. Physics Education Research Conference, 8(1), 1-14.

Halloun, I. (2001). Student Views about Science: A comparative Survey. Phoenix Series/Educational Research Center, Lebanese University, Beirut.

Hammer, D. (2000) Student Resources for Learning Introductory Physics. American Journal of Physics, 68(1), 52-59. https://doi.org/10.1119/1.19520

Hazari, Z., Tai, R. H., \& Sadler, P. M. (2007). Gender Differences in Introductory University Physics Performance: The Influence of High School Physics Preparation and Affective Factors. Science Education, 91(6), 847-876. https://doi.org/10.1002/sce.20223.

Hidi, S., Renninger, A., \& Krapp, A. (2004). Interest, a Motivational Variable that Combines Affective and Cognitive Functioning. In D. Y. Dai \& R. J. Sternberg (Eds.), Motivation, Emotion, and Cognition. Lawrence Erlbaum. 
Hofer, B. K., \& Pintrich, P. R. (2016). The Development of Epistemological Theories. Beliefs About Knowledge and Knowing and Their Relation to Learning. Review of Educational Research, 67(1), 88-140. https://doi.org/10.3102/00346543067001088

Holsti, O. R. (1969). Content Analysis for the Social Sciences and Humanities. Addison-Wesley.

Hong, Y., Chiu, C., Dweck, C. S., Lin, D. M.-S., \& Wan, W. (1999). Implicit Theories, Attributions, and Coping: A Meaning System Approach. Journal of Personality and Social Psychology, 77(3), 588-599. https://doi.org/10.1037/0022-3514.77.3.588

Kamins, M. L., \& Dweck, C. S. (1999). Person Versus Process Praise and Criticism: Implications for Contingent Self-Worth and Coping. Developmental Psychology, 35(3), 835-847. https://doi.org/10.1037/0012-1649.35.3.835

Krapp, A. (1992). Interesse, Lernen und Leistung. Neue Forschungsansätze in der Pädagogischen Psychologie. [Interest, Learning and Achievement. New Research Approaches in Educational Psychology.] Zeitschrift für Pädagogik, 38(5), 747-770.

Krüger, D., Parchmann, I., \& Schecker, H. (Eds.) (2014). Methoden in der naturwissenschaftsdidaktischen Forschung [Methods in Scientific Didactic Research]. Springer Spektrum.

Laukenmann, M., Bleicher, M., Fuß, S., Gläser-Zikuda, M., Mayring P., \& von Rhöneck, C. (2003). An Investigation of the Influence of Emotional Factors on Learning in Physics Instruction. International Journal of Science Education, 25(4), 489-507. https://doi.org/10.1080/09500690210163233

Lee, Y.-H., Heeter, C., Magerko, B., \& Medler, B. (2012). Gaming Mindsets: Implicit Theories in Serious Game Learning. Cyberpsychology, Behavior, and Social Networking, 15(4), 190-194. https://doi.org/10.1089/cyber.2011.0328

Leslie, S.-J., Cimpian, A., Meyer, M., \& Freeland, E. (2015). Expectations of Brilliance Underlie Gender Distributions Across Academic Disciplines. Science, 347(6219), 262-265. https://doi.org/ 10.1126/science.1261375

Lisberg, A., \& Woods, B. (2018). Mentorship, Mindset and Learning Strategies: An Integrative Approach to Increasing Underrepresented Minority Student Retention in a STEM Undergraduate Program. Journal of STEM Education, 19, 3. https://www.learntechlib.org/p/184625/

Lising L., \& Elby A. (2005). The Impact of Epistemology on Learning: A Case Study from Introductory Physics, American Journal of Physics, 73(4), 372-382. https://doi.org/10.1119/1.1848115

Lou, N. M., \& Noels, K. A. (2017). Measuring Language Mindsets and Modelling their Relations with Goal Orientations and Emotional and Behavioral Responses in Failure Situations. Modern Language Journal, 101(1), $214-243$. https://doi.org/10.1111/modl.12380

Mangels, J. A., Butterfield, B., Lamb, J., Good, C., \& Dweck, C. S. (2006). Why do Beliefs about Intelligence Influence Learning Success? A Social Cognitive Neuroscience Model. Social Cognitive and Affective Neuroscience, 1(2), 75-86. https://doi.org/10.1093/scan/nsl013

Marsh, H. W. (1990). The Structure of Academic Self-Concept - The Marsh/Shavelson Model. Journal of Educational Psychology, 82(4), 623-636. https://doi.org/10.1037/0022-0663.82.4.623

Marsh, H. W., \& Martin, A. J. (2011). Academic Self-Concept and Academic Achievement: Relations and Causal Ordering. British Journal of Educational Psychology, 81(1), 59-77. https://doi.org/10.1348/000709910X503501

Marshman, E., Kalender, Z. Y., Schunn, C., Nokes-Malach, T., \& Singh, C. (2017). A Longitudinal Analysis of Students' Motivational Characteristics in Introductory Physics Courses: Gender Differences. Canadian Journal of Physics, 96(4), 391405. https://doi.org/10.1139/cjp-2017-0185

May, D. B., \& Etkina, E. (2002), College Physics Students' Epistemological Self-Reflection and its Relationship to Conceptual Learning. American Journal of Physics, 70(12), 1249. https://doi.org/10.1119/1.1503377

Mayring, P. (2015). Qualitative Inhaltsanalyse: Grundlagen und Techniken [Qualitative Content Analysis: Basics and Techniques]. Beltz Verlag.

McCabe, J. A., Kane-Gerard, S., \& Friedman-Wheeler, D. G. (2020). Examining the Utility of Growth-Mindset Interventions in Undergraduates: A Longitudinal Study of Retention and Academic Success in a First-Year Cohort. Translational Issues in Psychological Science, 6(2), 132-146. https://doi.org/10.1037/tps0000228.

Mueller, C. M., \& Dweck, C. S. (1998). Praise for Intelligence Can Undermine Children's Motivation and Performance. Journal of Personality and Social Psychology, 75(1), 33-52. https://doi.org/10.1037/0022-3514.75.1.33

Muis, K. R., Bendixen, L. D., \& Haerle, F. C. (2006). Domain-Generality and Domain-Specificity in Personal Epistemology Research: Philosophical and Empirical Reflections in the Development of a Theoretical Framework. Educational Psychology Review, 18(1), 3-54. https://doi.org/10.1007/s10648-006-9003-6

Nakakoji, Y., \& Wilson, R. (2014). Maths is a Strong Predictor of STEM Attainment in First-Year University. Proceedings of the Australian Conference on Science and Mathematics Education (pp. 149-155), University of Sydney. https://openjournals.library.sydney.edu.au/index.php/IISME/article/view/7741/8077

O'Keefe, P. A., Dweck, C. S., \& Walton, G. M. (2018). Implicit Theories of Interest: Finding your Passion or Developing it? Psychological Science, 29(10), 1653-1664. https://doi.org/10.1177/0956797618780643.

Ortiz Alvarado, N. B., Rodríguez Ontiveros, M., \& Ayala Gaytán, E. A. (2019). Do Mindsets Shape Students' Well-Being and Performance? The Journal of Psychology: Interdisciplinary and Applied, 153(8), 843-859. https://doi.org/10.1080/00223980.2019.1631141 
Perkins, K., \& Gratny, M. (2010). Who Becomes a Physics Major? A Long-Term Longitudinal Study Examining the Roles of PreCollege Beliefs about Physics and Learning Physics, Interest, and Academic Achievement. AIP Conference Proceedings, 1289, 253-256. https://doi.org/10.1063/1.3515214

Potvin, P., \& Hasni, A. (2014). Interest, Motivation and Attitude towards Science and Technology at K-12 levels: A Systematic Review of 12 years of Educational Research. Studies in Science Education, 50(1), 85-129. https://doi.org/10.1080/03057267.2014.881626

Rice University (2018, March 29). Nobel laureate Carl Wieman: The Right Question Primes Students for Learning [Press release]. https://news.rice.edu/2018/03/29/nobel-laureate-carl-wieman-the-right-question-primes-students-for-learning

Salehi, S., Burkholder, E., Lepapage, G. P., Pollock, S., \& Wieman, C. (2019). Demographic Gaps or Preparation Gaps? The Large Impact of Incoming Preparation on Performance of Students in Introductory Physics. Physical Review Physics Education Research, 15(2), 020114. https://doi.org/10.1103/PhysRevPhysEducRes.15.020114

Schiefele, U., \& Wild, K. P. (1994). Lernstrategien im Studium: Ergebnisse zur Faktorenstruktur und Reliabilität eines neuen Fragebogens [Learning Strategies during Studies: Results on the Factor Structure and Reliability of a New Questionnaire]. Zeitschrift für Differentielle und Diagnostische Psychologie, 15(4), 185-200.

Schmidt, F. T. C., Fleckenstein, J., Retelsdorf, J., Eskreis-Winkler, L., \& Möller, J. (2019). Measuring grit: A German Validation and a Domain-Specific Approach to Grit. European Journal of Psychological Assessment, 35(3), 436-447. https://doi.org/10.1027/1015-5759/a000407

Schwamberger, T. M. (2017). Mindsets von Schülerinnen und Schülern im Unterrichtsfach Physik - eine Interviewstudie [Students' Mindsets in the School-Subject of Physics - An Interview Study] [Unpublished Thesis, University of Vienna].

Scott, M. J., \& Ghinea, G. (2014). On the Domain-Specificity of Mindsets: The Relationship between Aptitude Beliefs and Programming Practice. IEEE Transactions on Education, 57(3), 169-174. https://doi.org/10.1109/TE.2013.2288700

Seligman, M. E., Abramson, L.Y., Semmel, A., \& von Baeyer, C. (1979). Depressive Attributional Style. Journal of Abnormal Psychology, 88(3), 242-247. https://doi.org/10.1037/0021-843X.88.3.242

Sisk, V. F., Burgoyne, A. P., Sun, J., Butler, J. L., \& Macnamara, B. N. (2018). To What Extent and Under Which Circumstances Are Growth Mind-Sets Important to Academic Achievement? Two Meta-Analyses. Psychological Science, 29(4), 549-571. https://doi.org/10.1177/0956797617739704

Sriram, R. (2013). Rethinking Intelligence: The Role of Mindset in Promoting Success for Academically High-Risk Students. Journal of College Student Retention: Research, Theory and Practice, 15(4), 515-536. https://doi.org/10.2190/CS.15.4.C

Stathopoulou, C., \& Vosniadou, S. (2007). Exploring the Relationship between Physics-Related Epistemological Beliefs and Physics Understanding. Contemporary Educational Psychology, 32(3), 255-281. https://doi.org/10.1016/j.cedpsych.2005.12.002

Weiner, B. (1974). Achievement motivation and attribution theory. General Learning Press.

Xu, K., Koorn, P., De Koning, B., Skuballa, I., Lin, L., Henderikx, M., Marsh, H., Sweller, J., \& Paas, F. (2020). A Growth Mindset Lowers Perceived Cognitive Load and Improves Learning: Integrating Motivation to Cognitive Load. Journal of Educational Psychology. https://doi.org/10.1037/edu0000631

Yeager D. S., \& Walton, G. M. (2011). Social-Psychological Interventions in Education: They're Not Magic. Review of Educational Research, 81(2), 267-301. https://doi.org/10.3102/0034654311405999

Yeager, D. S., \& Dweck, C. S. (2012). Mindsets that Promote Resilience: When Students Believe that Personal Characteristics Can Be Developed. Educational Psychologist, 47(4), 302-314. https://doi.org/10.1080/00461520.2012.722805

Yeager, D. S., Hanselman, P., Walton, G. M., Murray, J. S., Crosnoe, R., Muller, C., Tipton, E., Schneider, B., Hulleman, C. S., Hinojosa, C. P., Paunesku, D., Romero, C., Flint, K., Roberts, A., Trott, J., Iachan, R., Buontempo, J., Man Yang, S., Carvalho, C. M., ... Dweck, C. S. (2019). A National Experiment Reveals where a Growth Mindset Improves Achievement. Nature, 573, 364-369. https://doi.org/10.1038/s41586-019-1466-y

Yeager, D. S., Romero, C., Paunesku, D., Hulleman, C. S., Schneider, B., Hinojosa, C., Lee, H. Y., O’Brien, J., Flint, K., Roberts, A., Trott, J., Greene, D., Walton, G. M., \& Dweck, C. S. (2016). Using Design Thinking to Improve Psychological Interventions: The Case of the Growth Mindset during the Transition to High School. Journal of Educational Psychology, 108(3), 374-391. https://doi.org/10.1037/edu0000098

Yeager, D. S., Trzesniewski, K. H., \& Dweck, C. S. (2013). An Implicit Theories of Personality Intervention Reduces Adolescent Aggression in Response to Victimization and Exclusion. Child Development, 84(3), 970-988. https://doi.org/10.1111/cdev.12003

Zeeb, H., Ostertag, J., \& Renkl, A. (2020). Towards a Growth Mindset Culture in the Classroom: Implementation of a LessonIntegrated Mindset Training. Education Research International, 2020, 8067619. https://doi.org/10.1155/2020/8067619

Zhu, S., Zhuang, Y., \& Cheung, S.-H. (2020). Domain Specificity or Generality: Assessing the Chinese Implicit Theories Scale of Six Fundamental Psychological Attributes. Frontiers in Psychology, 11, 142. https://doi.org/10.3389/fpsyg.2020.00142 